\title{
Association of Wealth and Mortality Due to Cardiovascular Diseases Thank You. Dr. Wilson
}

\author{
Miki Tokunaga ${ }^{1}$, Toru Takahashi ${ }^{2, *}$, Ram B. Singh $^{3}$, Elena Gerasimova ${ }^{4}$, Fabien De Meester ${ }^{5}$ and \\ Douglas W. Wilson ${ }^{6}$ \\ ${ }^{1}$ Department of Nutrition and Health Sciences, Fukuoka Women's University, Fukuoka, Japan \\ ${ }^{2}$ Department of Nutrition, Graduate School of Human Environment Science, Fukuoka Women's University, Japan \\ ${ }^{3}$ Halberg Hospital and Research Institute, Moradabad, India \\ ${ }^{4}$ Faculty of Pediatrics, State Medical Academy of N.N. Burdenko in Voronezh, Russia \\ ${ }^{5}$ The Tsim Tsoum Institute, Krakow, Poland \\ ${ }^{6}$ School of Medicine, Pharmacy and Health, Durham University, UK
}

\begin{abstract}
Industrialization and urbanization may be associated with increase in income, resulting in increased consumption of ready-prepared Western foods, meat and eggs and cola drinks and decreased intake of traditional foods; whole grains, and vegetables. There is also associated greater use of automobiles causing sedentary behaviours, due to decreased occupational physical activity. These diet and lifestyle factors predispose obesity and central obesity which is a risk factor of cardiovascular diseases (CVDs) mortality.
\end{abstract}

Keywords: Wealth, health, sedentary behaviour, hypertension, heart disease.

\section{WORLD MORTALITY}

The morbidity and mortality due to cardiovascular diseases (CVDs) and other chronic diseases have become a global public health problem [1-6]. Mortality and burden of disease estimates for WHO Member States in 2008 revealed that $36 \cdot 1$ million deaths per year occur as a result of noncommunicable disease (NCDs), which are mainly due to CVDs [2]. These estimates represent almost two out of three deaths per year worldwide. Approximately, two-thirds (63\%) of premature deaths in adults (aged 15-69 years), and three out of four of all adult deaths are attributable to NCDs in the world (Fig. 1). However, some experts misinterpret the WHO estimates and proposed that, of total deaths, 22.4 million arise in the poorest countries, and 13.7 million in highincome and upper-middle-income countries and therefore poverty may be the major cause of NCDs (Fig. 1) [2]. It seems that comparing mortality data among rich and 'poors' within countries, would not support these views about poverty and mortality [1-7].

\section{WEALTH AND DEATHS}

The health budget in USA was US\$2.7 trillion in 2011, which is $\$ 8700$ for every person in the country, and

*Address correspondence to this author at the Department of Nutrition, Graduate School of Human Environment Science, Fukuoka Women's University, Fukuoka, Japan; Tel: +81- 92-661-2411, Fax: +81-92-661-2415;

E-mail: takahashi@fwu.ac.jp represents $17 \cdot 9 \%$ of the economy, that is far greater than any other economically advanced country [1, 3]. However, it made world news that despite spending more on health care per person than other high-income countries, many people in United States, die sooner, are least likely to reach the age of 50 years, and have higher rates of disease or injury [3]. Unfortunately, Americans are less healthy from birth to 75 years of age than people in 16 other economically wealthy countries, if judged by health alone. This health disadvantage has been getting worse for 30 years, especially among women, as disclosed in a report released on Jan 9 from the US National Research Council and Institute of Medicine [3]. This report compared comprehensive mortality and morbidity data from USA with affluent democratic countries; Australia, Canada, France, Italy, most of the Nordic countries, Spain, and the UK. Life expectancy is shorter at birth for American men than for men in any of the other 16 countries, and American women fare little better. Surprisingly, Denmark is the only country that has a lower life expectancy for women at birth. In nine key areas of health; infant mortality and low birth weight; injuries and homicides; teenage pregnancies and sexually transmitted infections; HIV/AIDS prevalence; drug-related deaths; obesity and diabetes; heart disease; chronic lung disease; and disability, the United States fare least well, or is near the bottom of the tables. This health disadvantage applies to those with health insurance, a college education, higher incomes, and healthy behaviours as well as to those without [3]. Under these circumstances, it is not clear, how the UNO is planning to achieve Millennium 


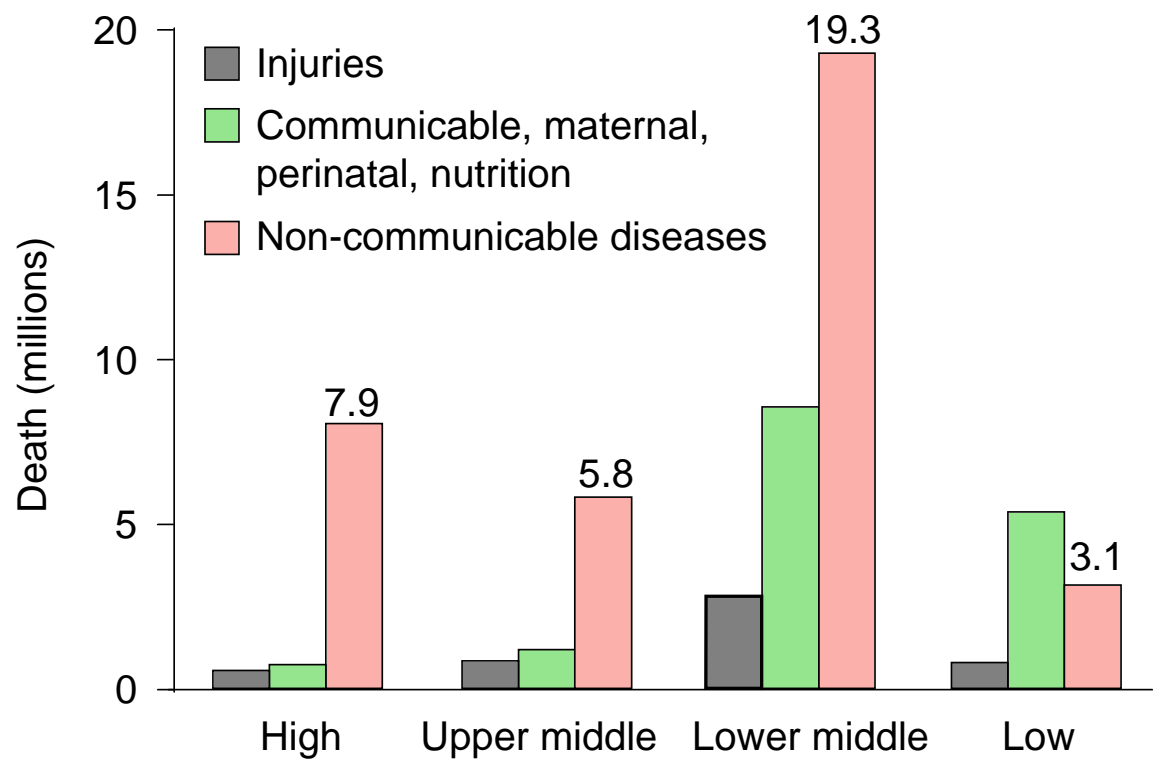

Country Income groups

Fig. (1). Broad causes of death according to WHO 2010.

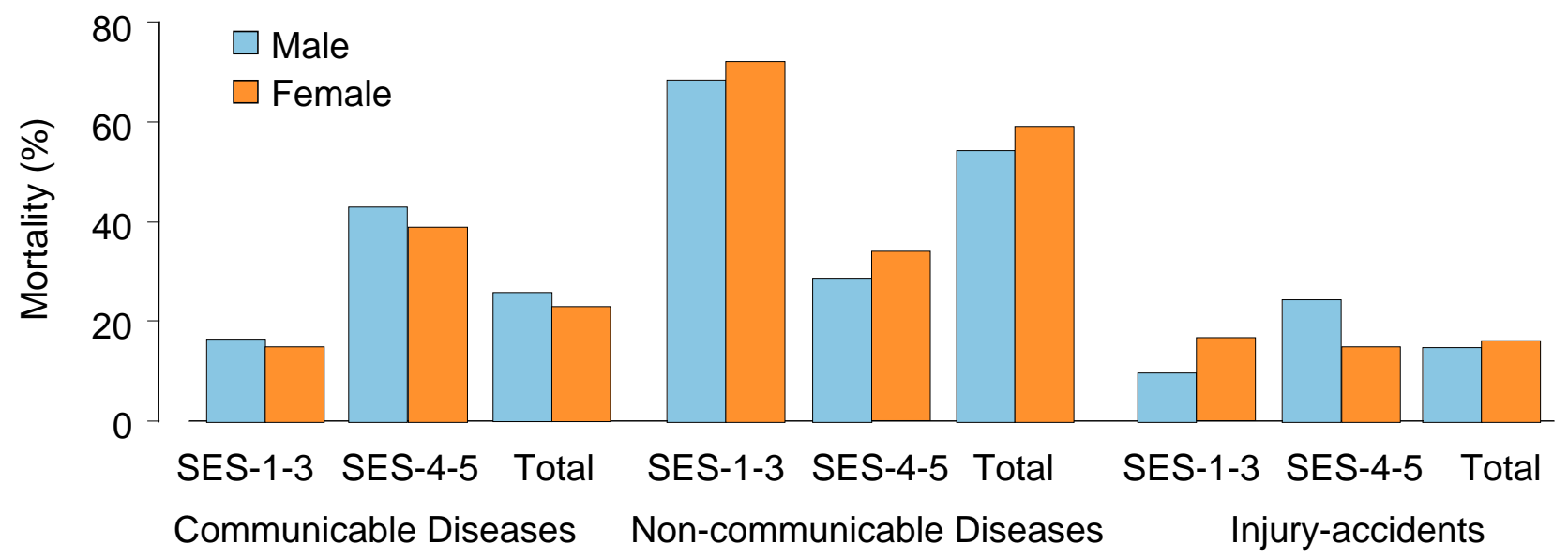

Fig. (2). Social classes and mortality due to non-communicable diseases in India.

Development Goals for reducing avoidable mortality due to NCDs by $25 \%$ by 2025 (the 25 by 25 goal) [4].

We share the same views and reported that poor economic status does not appear to be the cause of deaths due to NCDs [5]. This Indian study shows that $57.0 \%$ of deaths in adults (aged 25-64 years) were due to NCDs, (including $31.0 \%$ due to CVDs), $25.5 \%$ due to communicable diseases, and $15.9 \%$ due to injury and accidents, indicating that our findings on deaths due to NCDs are similar to WHO estimates (Fig. 2) [2, 5]. Poor social classes 4 and 5 had lowest prevalence of deaths and social classes 1-3, having greater income had highest prevalence of deaths due to NCDs (Fig. 3). It seems that sedentary behaviours, excess salt intake, and other typical Western dietary habits were significantly more common among decedents belonging to wealthy social classes 1-3, compared to those within poor social classes 4 and 5. Lack of knowledge regarding health education was significantly more common among decedents in poor social classes, who died more often due to communicable diseases. The study also revealed that deaths associated with diabetes mellitus and due to circulatory diseases were significantly more common among wealthy social classes 13 , compared to poor social classes 4 and 5 [5]. In a recent report of the American Heart Association [6], after adjustment, population attributable fractions for CVD mortality were as follows; for high blood pressure, 1: 40.6\% (95\% confidence interval [CI], 24.5-54.6); for smoking $13.7 \%$ (95\% CI, 4.8-22.3); for unhealthy diet $13.2 \%$ (95\% CI,3.529.2); for sedentary behaviour $11.9 \%$ (95\% CI, 1.3-22.3) and for high glucose; $8.8 \%$ (95\% CI, 2.1-15.4). The United Nations, High Level Meeting (UN-HLM) held in Sept 2011, on deaths and disability due to NCDs, may invoke some controversies because the United Nations is also expecting to achieve the development goals without a proper agenda for total health care $[4,7]$. The basic health behaviours related risk factors resulting in death and disability and discussion 


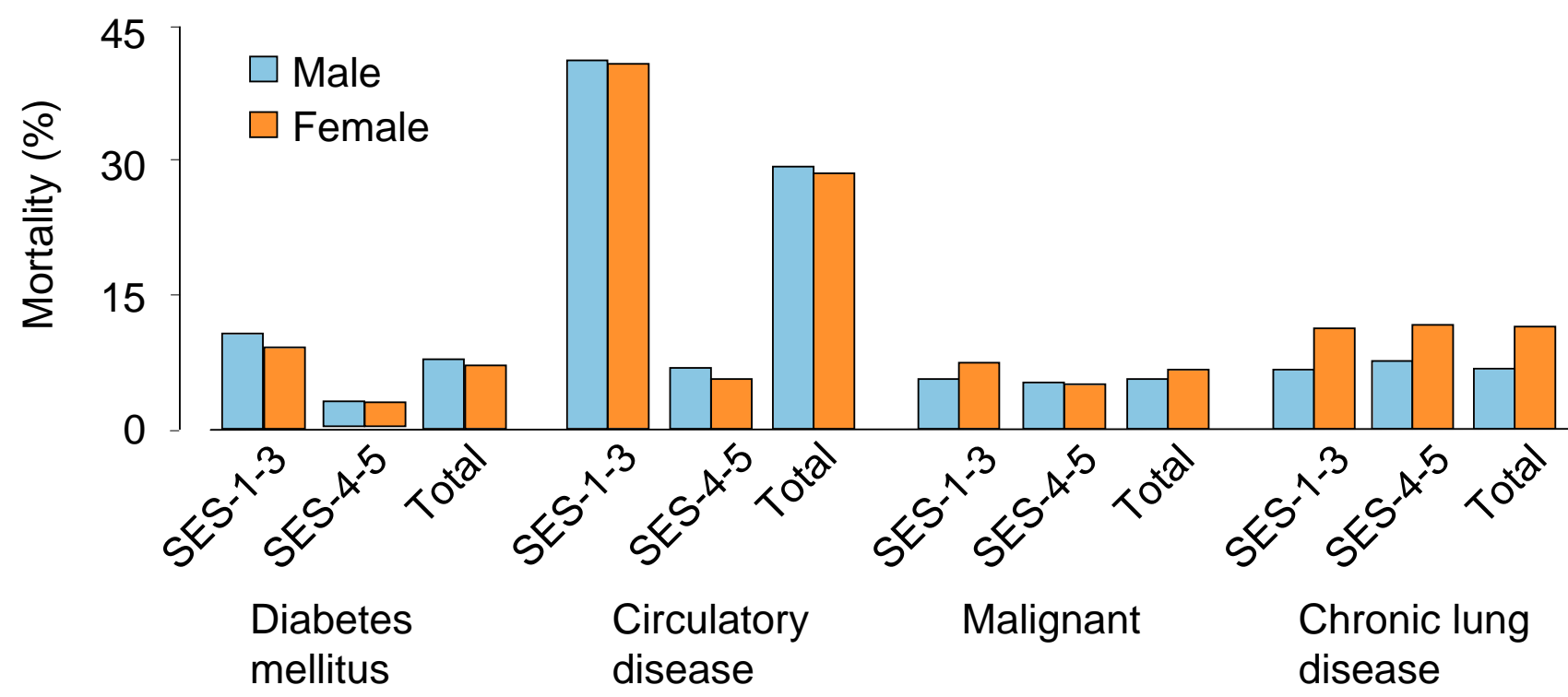

Fig. (3). Causes of deaths due to noncommunicable diseases according to classification by UN HLM, 2011, in relation to the social classes.

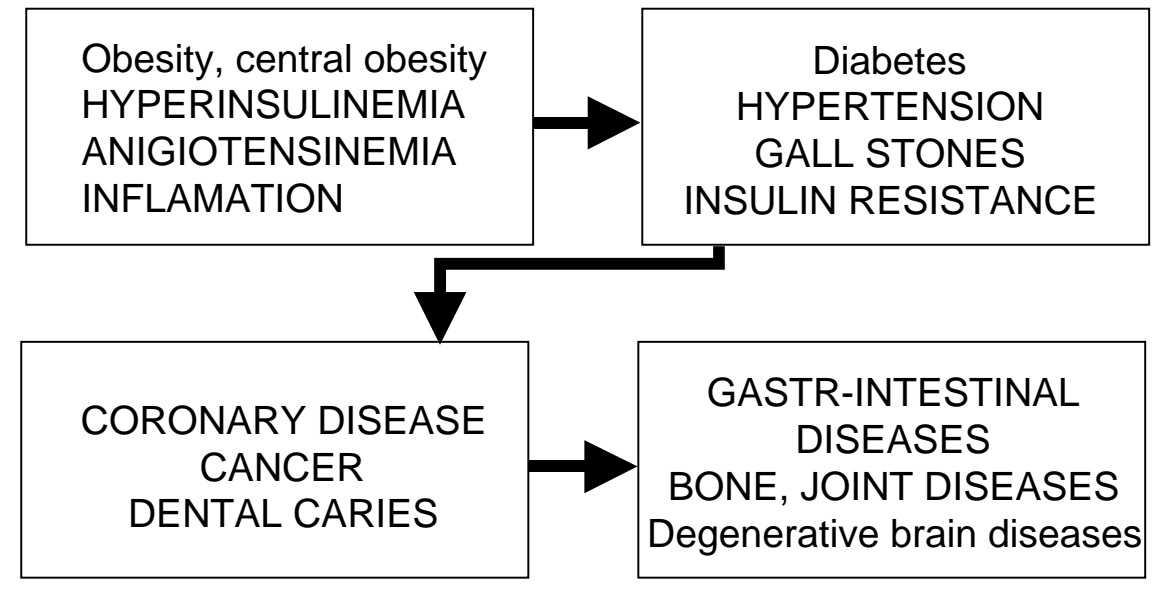

Fig. (4). Emergence of chronic diseases due to interactions of gene and environment (Singh et al., 1999, modified from Burkitt and Trowell).

on existing health promotion policies in the developed countries, which are also followed by the developing countries, were not given due consideration [3-7]. Nutrition in transition from Homo sapiens to Homo economicus indicate that there is need to target total health including social, mental and spiritual health for prevention of CVDs and sustainable human development to achieve Millennium Development Goals [7-10].

The above studies indicate that lower income as such does not appear to be the cause of CVDs. In the 1980s, in Kerala State, India, maternal and child mortality rates were lowest and life expectancy and literacy rates were as good as in developed countries in association with rising prevalence of CVDs, but the people were not very wealthy compared to other states of India $[11,12]$. There is consistent evidence that wealthy social classes 1-3 in both rural and urban areas have greater prevalence of risk factors of NCDs compared to lower social classes as revealed by the Five City study including Kerala and other studies [11-14]. However, in developed countries the risk is reversed, causing higher prevalence of deaths due to NCDs among lower social classes compared to higher social classes, due to learning and buying of health behaviour [15]. In a more recent study among 7519 subjects with self-reported CAD or stroke event from countries with varying income levels, the prevalence of healthy lifestyle behaviours was low, with even lower levels in poorer countries [16]. However, this study did not report on attributes of social class; education, housing, occupation, consumer durables and household income which appear to be important determinants of health behaviours [17-20]. One recent study showed that the intake of prudent foods was significantly lower and that of Western foods, significantly higher among patients with NCDs compared to decedents who died due to injury and accidents [21] (Table 1). The increased consumption of Western foods in most of the population is because convenience, taste and flavour of foods.

\section{HOW TO APPROACH THE PROBLEM?}

There does not appear to be a proper approach for assessment, planning and management of NCDs. The obstacles in achieving desired health goals are great and largely not discussed, because many experts are not willing to under- 
Table 1. Food Intakes and w-6/w-3 Fatty Acid Ratio of Diet in Relation to Causes of Death based on Assessment by Dietary Diaries of the Spouse and Questionnaires Filled by the Nutritionist

\begin{tabular}{|c|c|c|c|c|c|}
\hline Causes of death & Prudent Diet & Western Type Diet & Total Foods & Score & w-6/w-3 Ratio \\
\hline $\begin{array}{l}\text { Communicable } \\
\text { Diseases.(n=372) }\end{array}$ & $806 \pm 237$ & $256 \pm 28$ & $1062 \pm 198$ & $7.26 \pm 2.7$ & $38.2 \pm 6.6$ \\
\hline Malignant ( $\mathrm{n}=77$ ) & $715 \pm 241$ & $412 \pm 53$ & $1127 \pm 311$ & $6.44 \pm 2.5$ & $42.2 \pm 6.8$ \\
\hline Circulatory $(\mathrm{n}=406)$ & $757 \pm 245$ & $437 \pm 47$ & $1194 \pm 318$ & $6.81 \pm 2.6$ & $45.3 \pm 8.3$ \\
\hline Chronic lung diseases(97) & $705 \pm 202$ & $405 \pm 41$ & $1110 \pm 302$ & $6.25 \pm 2.2$ & $42.0 \pm 7.4$ \\
\hline Kidney diseases $(\mathrm{n}=163$ & $617 \pm 188$ & $505 \pm 55$ & $1122 \pm 325$ & $5.72 \pm 1.8$ & $41.8 \pm 6.1$ \\
\hline $\mathrm{n}=837$ & \multicolumn{5}{|c|}{ Women(Mean \pm Standard deviation)g/day } \\
\hline Injury-accidents $(\mathrm{n}=139)$ & $822 \pm 234$ & $186 \pm 23$ & $1008 \pm 224$ & $8.40 \pm 2.2$ & $25.5 \pm 5.7$ \\
\hline Communicable diseases $(\mathrm{n}=194)$ & $736 \pm 237$ & $218 \pm 33$ & $954 \pm 201$ & $7.51 \pm 1.9$ & $34.5 \pm 5.6$ \\
\hline \multicolumn{6}{|l|}{$\operatorname{NCDs}(\mathrm{n}=502)$} \\
\hline Malignant(n=54) & $657 \pm 197$ & $305 \pm 35$ & $962 \pm 221$ & $6.70 \pm 1.8$ & $41.6 \pm 6.8$ \\
\hline Circulatory $(n=240)$ & $655 \pm 205$ & $332 \pm 41$ & $987 \pm 218$ & $6.68 \pm 1.7$ & $44.5 \pm 7.5$ \\
\hline Chronic lung diseases $(n=95)$ & $660 \pm 180$ & $382 \pm 48$ & $1029 \pm 180$ & $6.12 \pm 1.3$ & $40.0 \pm 6.5$ \\
\hline
\end{tabular}

stand that NCDs are linked to the way our health behaviours is; regarding eating, exercising, tobacco consuming and the way of living as well as to the accessibility and organization of health care by the governments. The challenge is how to develop tasty, flavoured, convenient health foods for prevention of CVDs.

Millions of deaths occur every year due to a lack of health education and poor health public policies because people and populations living with scant resources, have no opportunity for health education due to poor public health services [16-18]. These findings further confirm the old hypothesis that emergence of NCDs may have a sequence during transition from under-nutrition and poverty to affluence; (Fig. 4). Western diet in conjunction with sedentary behaviours results in overweight and central obesity first with an increase in wealth, causing deficiency of angiotensin, and adiponectin, hyperinsulinemia, increase in interleukin-6(IL6), and tumor necrosis factor-alpha(TNF-alpha), followed by pre-metabolic syndrome, dyslipidemia, diabetes and insulin resistance, hypertension, and gall stones. Coronary artery disease (CAD) and cancer, come later and finally there is emergence of dental caries, bone and joint diseases, gastrointestinal diseases, neuropsychiatric disorders and dementia.

We need to educate the public health policy makers about, how to provide prudent foods at affordable cost by the food industry and farmers and low cost high alcohol wines, to decrease the consumption of highly concentrated alcoholic beverages [5]. Free community centres for exercise, yoga and meditation as well as tax relief to hotels, motels and resorts providing these services at affordable cost to 'poors', in a 'no tobacco' world would be a great step forward in providing better total health as well as for prevention of CVDs. Further steps may be to develop housing so as to promote physical activity without the need for automobiles for routine household shopping. The challenges of how to develop "Functional Food Security" by a changed food industry and inexpensive spare time and occupational physical activity across the whole world for sustainable human development and prevention of CVDs may be accomplished by these steps [1-5]. In brief, this sequence of development of CVDs may be altered by learning and regular practise of methods of prevention by alteration in public health policies related to 
affordable community gymnasiums and yoga centres, no tax health food industry in a 'no tobacco world'. The aim and efforts should be made for achieving total health including social, mental and spiritual health, apart from the physical health [15-21].

\section{CONFLICT OF INTEREST}

Conflict of interest has not been declared by any of the authors.

\section{ACKNOWLEDGEMENTS}

Acknowledgements are due to International College of Nutrition and the Tsim Tsoum Institute for providing logistic support to write this article.

\section{REFERENCES}

[1] Editorial. Wealth but not health in USA. Lancet 2013; 381: 177.

[2] WHO. Mortality and burden of disease estimates for WHO Member States in 2008. Geneva: World Health Organization, 2010.

[3] U.S. Health In: International Perspective. Shorter Lives, Poorer Health. National Academy of Sciences, USA 2013. (For the report on US healthdisadvantage see http://www. nap. edu/ catalog.php? record_id=13497; For the US prevention strategy see http://www. healthcare.gov/prevention/nphpphc/strategy/report.pdf

[4] Beaglehole R, Bonita R, Alleyne G, et al. UN High-Level Meeting on Non-Communicable Diseases: addressing four questions. Lancet 2011; 378: 449-55.

[5] Singh RB, Anjum B, Takahashi T, et al. Poverty is not the absolute cause of deaths due to non-communi- cable diseases NCDs. World Heart J 2012; 4: 221-36.

[6] The "Heart Disease and Stroke Statistics--2013 Update" and the Need for a National Cardiovascular Surveillance System. Circulation 2013; 127: 21-3.

[7] UN. Keeping the promise: united to achieve the Millennium Development Goals. Available from:http://www.un.org/en/mdg/summit2010/pdf/ZeroDraftOutcomeDocument 31May2010rev2.pdf. [Accessed Jan 28, 2013].
[8] Singh RB, Takahashi T, Nakaoka T, et al. Nutrition in transition from Homo sapiens to Homo economicus. Open Nutra J 2013; 6: 617.

[9] Horton R. Non-communicable diseases: 2015 to 2025. Lancet 2013; 381: 509-10.

[10] Clark H. NCDs: a challenge to sustainable human development. Lancet 2013; 381: 510-1.

[11] Pednekar MS, Gupta R, Gupta PC. Illiteracy, low educational status and cardiovascular mortality in India. BMC Public Health 2011; 11: 567.

[12] Singh RB, Beegom R, Mehta AS, et al. Social class, coronary risk factors and undernutrition, a double burden of diseases, in women during transition, in five Indian cities. Int J Cardiol 1999; 69: 13947.

[13] Singh RB, Sharma JP, Rastogi V, et al. Social class and coronary disease in a rural population of north India. Eur Heart J 1997; 18: 588-95.

[14] Teo K, Chow CK, Vaz M, Rangarajan S, Yusuf S. The Prospective Urban Rural Epidemiology (PURE) study: examining the impact of societal influences on chronic non communicable diseases in low, middle, and high-income countries. Am Heart J 2009; 158: 1-7.

[15] Kesteloot H. Social class, all cause and cardiovascular mortality. Acta Cardiol 2004; 59: 117.

[16] Teo K, Lear S, Islam S, et al. Prevalence of a healthy lifestyle among individuals with cardiovascular disease in high-, middleand low-income countries: The Prospective Urban Rural Epidemiology (PURE) Study. JAMA 2013; 309: 1613-21.

[17] Tokunaga M, Takahashi T, Singh RB, et al. Diet, Nutrients and noncommunicable diseases. Open Nutra J 2012; 5: 146-59.

[18] Takahashi T, Singh RB, Meester FD, Wilson D. How the 'West' can overcome unhealthy behaviours to prevent chronic diseases. $\mathrm{J}$ Socialomics 2013; 2: e114.

[19] Singh RB, Fedacko J, Vargova V, et al. Singh's verbal autopsy questionnaire for assessment of causes of death, social autopsy, tobacco autopsy, and dietary autopsy based on medical records and interview. Acta Cardiol 2011; 66: 471-81.

[20] Moodie R, Stuckler D, Monteiro C, et al. Profits and pandemics: prevention of harmful effects of tobacco, alcohol, and ultraprocessed food and drink industries. Lancet 2013; 381:670-9.

[21] Fedacko J, Vargova V, Singh RB, et al. Association of high w- $6 / \mathrm{w}-$ 3 fatty acid ratio diet with causes of death due to noncommunicable diseases among urban decedents in North India. Open Nutra J 2012; 5: 113-23. 